\title{
Evaluation of Condom Use and Associated Factors among Adult HIV Clients in Maiduguri, North Eastern Nigeria: A Comparative Cross Sectional Study
}

\author{
Ballah Akawu Denue, Salisu Aliyu Kwayabura², David Bukbuk³, Umaru Inuwa², \\ Babajide Babatunde Ajayi ${ }^{4}$ \\ ${ }^{1}$ Deparment of Medicine, University of Maiduguri Teaching Hospital, Maiduguri, Nigeria \\ ${ }^{2}$ Department of Obstetrics and Gynaecology, University of Maiduguri Teaching Hospital, Maiduguri, Nigeria \\ ${ }^{3}$ Deparment of Microbiology, University of Maiduguri, Maiduguri, Nigeria \\ ${ }^{4}$ Department of Immunology, University of Maiduguri Teaching Hospital, Maiduguri, Nigeria \\ Email: $\underline{\text { d akawu@yahoo.co.uk }}$
}

Received 25 January 2014; revised 25 February 2014; accepted 20 March 2014

Copyright (C) 2014 by authors and Scientific Research Publishing Inc.

This work is licensed under the Creative Commons Attribution International License (CC BY).

http://creativecommons.org/licenses/by/4.0/

(c) (i) Open Access

\section{Abstract}

Objective: To assess the pattern of condom use among HAART naive and experienced patients in north eastern Nigeria. Methods: An interviewer-administered questionnaire was used to assess the pattern of condom use among 201 HIV clients. Participants included for this comparative cross sectional study were divided into two group: HAART experienced participants that had been on therapy for at least 12 months and HAART naive participants that had been registered at least 3 months before the beginning of the study. Results: Almost half of the HAART naive and substantial proportion of HAART experienced couples never used condom. Few $(13.4 \%)$ HAART experienced and $16.5 \%$ naive participants always used condom. Inconsistent condom use among HAART naive and experienced partners was $38.8 \%$ and $\mathbf{4 1 . 8 \%}$ respectively. Spouse notification of HIV was significantly associated with the use of condoms ( $p=0.02$; OR 1.32, 95\% CI: $1.06-1.64)$. The stepwise logistic regression indicated that female (OR 2.40; CI: 1.09 - 3.82), partner notification of HIV seropositive status (OR 1.32; CI: 1.06 - 1.64, yes versus none), occupation as a civil servant (OR 1.40; CI: 0.15 - 1.05), are factors independently associated with condom use in our studied participants. Conclusion: We report that condom use is uncommon among HIV clients in our environment. Condom is significantly influenced by partner notification of HIV seropositive status, occupation as a civil servant and female gender. This study supports an absence of association between condom 
uptake and HAART use. Intensive and regular condom counselling for every HIV-positive outpatient who attends the clinic in our environment is expedient. We recommend interventions directed at increasing condom use among HIV clients in our environment.

\author{
Keywords
}

Condom Use, HIV, AIDS

\title{
1. Introduction
}

Despite numerous efforts made over the last several years to halt HIV/AIDS epidemic through increased access to treatment, educational and policy changes, the burden of HIV/AIDS is enormous especially in sub-Saharan Africa, with $>60 \%$ of all HIV infections in the world occurring in this region [1]-[4]. In Nigeria, the reported HIV sero-prevalence of $4.1 \%$ among ante-natal clinic attendees in 2010 translates to 3.1 million people living with HIV/AIDS (PLWHA) [5]. However despite this high figure, condom use in Nigeria remains alarmingly very low at $25 \%$ and $11 \%$ for sexually active males and females respectively [6]. To our knowledge, condom use among HIV patients has not been reported in our environment in spite of its peculiar socio demographic characteristics [7]. Despite increased awareness of HIV infection and access to ART, condom use as a preventive measure among HIV patients has not been reported in north eastern Nigeria. Meta analysis of condom use and HAART has been reported to vary with belief about the efficacy of HAART in preventing infection [8]. Initiation of HAART has been reported to be associated with increased sexual risk behaviour [9]. Studies in the developed world suggested that individual's awareness of their HIV sero-positive status is associated with decrease sexual risk behaviour [8] [10]. On the contrary, a report from developing countries indicated that patients' awareness of their HIV sero-positive status including access to HAART has not led to significant risky sexual behaviour [11]. However, a subset of PLWHA is still engaged in unprotected intercourse, and hence the potential risk for HIV transmission persists [11] [12].

To provide effective measures that diminish HIV transmission, it is important to study the knowledge of mechanisms of HIV transmission, sexual behaviour and condom use among heterosexual HIV-positive patients.

With reported high prevalence of HIV infection in Nigeria and the dearth of information on condom use and other preventive measures such as pre-exposure prophylaxis, it becomes expedient to understand the pattern of condom use among HAART naive and experienced patients in North eastern Nigeria with the view of instituting appropriate secondary preventive measures.

\section{Patients and Methods}

\subsection{Study Setting}

A hospital based cross sectional study was conducted at HARVARD PEPFAR (Presidential Emergency Plan For AIDS Relief) supported HIV clinic at the University of Maiduguri Teaching Hospital, a tertiary health institution designated as a centre of excellence for infectious diseases in North eastern Nigeria.

\subsection{Study Participants}

The study participants were adult clients aged 18 years and above, attending an outpatient HIV clinic of the hospital. Patients included in this study were divided into two groups; HAART experienced participants that had been on therapy for at least 12 months and The HAART naive participants that had registered at least 3 months before the time of the study.

\subsection{Measurements}

The dependent variable was "condom use" (use of condom in sexual act in the last three months prior to the study). The condom use was further stratified into consistent condom use (use of condom in every sexual act) and inconsistent condom use (use of condom in some sexual act). The independent variables include socio 
demographic characteristics such as age, sex, marital status, residence (urban/rural), employment status (employed/unemployed); relational and behavioural factors such as type of partners (spouse/friend/commercial partners), disclosure of HIV status to partner. Social habit (ever smoked/never smoked cigarette, regular drinker and social drinker of alcohol or wine/no ingestion of alcohol).

\subsection{Data Collection}

A structured interview administered questionnaire prepared in English was used to collect data. Information from participants that did not understand English language was obtained through an interpreter that understands their local languages. Trained counsellors interviewed the participants in an isolated private room within the clinic complex.

\subsection{Data Analysis}

Data was entered and cleaned in Microsoft office excel version 2007 windows and analyzed by SPSS version 16. Bivariate analysis was carried out to determine the association of each independent variable on the dependent variable and those who had $<0.2$ level of significance were used in the final models. Stepwise multiple logistic regression analysis was used to determine the presence of association, with statistical significance set at $<0.05$. Odd ratio and $95 \%$ confidence interval were also determined.

\subsection{Ethical Consideration}

Permission to conduct this study was obtained from the institutions ethical committee. Respondents were informed about the purpose, procedure, risks and benefits, and the private and confidential nature of the study. Participation was voluntary and verbal informed consent was obtained from each respondent.

\section{Result}

\subsection{Socio-Demographic and Enrolment Characteristics by HAART Exposure}

A total of 201 clients were approached for this comparative cross sectional study. Out of these 170 participants participated, including 67 Highly Active Antiretroviral Therapy (HAART) naive and 103 HAART experienced. A total of 31 participants either refused to participate or declined to respond to some of the questions regarding their sexuality, and were excluded.

The sex distribution of the participants was not comparable; this trend was maintained with respect to HAART exposure. The mean ages of the studied participants was $35.83 \pm 8.37$ (20 - 63), HAART naive with mean age of $33.75 \pm 7.79$ were significantly younger than HAART experienced that had mean age of $37.22 \pm$ 8.49, $\mathrm{p}<0.05$.

Most of the patients were residents of urban areas (75.3\%). A substantial proportion of the HAART naive cohort had secondary education (38.8\%), while tertiary education was the predominant literacy level in HAART experienced cohort (46.6\%). Married participants constituted $42.9 \%$ of the participants; they contributed the highest participants in both HAART naive and experienced cohort. Patients in the sample held a variety of jobs ranging from civil service self/private employment to unskilled or artisan. Civil servants constituted the majority in HAART experienced, while unemployed cohort constituted one out of every three HAART naive patients (32.8\%). Socio-demographic and enrolment characteristics of the participants by HAART exposure is as shown in Table 1.

\subsection{Sexual Behaviour and Condom Use among Participants}

At the time of the interview, 53.7\% of HAART naive and 39.8\% of HAART experienced participants had multiple sexual partners, excluding males married in polygamous setting. Mean numbers of sex partners were $3.06 \pm$ 1.87 for men and $3.04 \pm 1.51$ for women. Significantly more females had multiple sexual partners in the HAART naive and males in the HAART experienced cohort. Ten men (14.9\%) among HAART naive and 17 (16.5\%) HAART experienced reported having paid for sex with a woman, and similar proportion of HAART naive and $24.3 \%$ of HAART experienced women reported having provided sex in exchange for money. Condom 
Table 1. Participant’s enrolment, sociodemographic characteristics by HAART status.

\begin{tabular}{|c|c|c|c|}
\hline Variables & $\begin{array}{c}\text { HAART naive ( } \mathrm{n}=67) \\
\mathrm{N}(\%)\end{array}$ & $\begin{array}{c}\text { HAART experienced }(\mathrm{n}=103) \\
\mathrm{N}(\%)\end{array}$ & $\begin{array}{c}\text { Total }(\mathrm{n}=170) \\
\mathrm{N}(\%)\end{array}$ \\
\hline \multicolumn{4}{|l|}{ Sex } \\
\hline Male & $29(43.3)$ & $49(47.6)$ & $78(45.9)$ \\
\hline Female & 38 (56.7) & $54(52.4)$ & $92(54.1)$ \\
\hline \multicolumn{4}{|l|}{ Age group (years) } \\
\hline $18-25$ & $13(19.4)$ & $08(7.8)$ & $21(12.4)$ \\
\hline $26-35$ & $29(43.3)$ & $33(32.0)$ & $62(36.5)$ \\
\hline $36-45$ & $21(31.3)$ & $43(41.8)$ & $64(37.7)$ \\
\hline $46-55$ & $04(6.0)$ & $13(12.6)$ & $17(10.0)$ \\
\hline $56-65$ & 00 & $06(5.8)$ & $06(3.5)$ \\
\hline Mean age \pm SD & $33.75 \pm 7.79(20-50)$ & $37.22 \pm 8.49(20-60)$ & $35.83 \pm 8.37(20-63)$ \\
\hline \multicolumn{4}{|l|}{ Residence } \\
\hline Urban & $45(67.2)$ & $83(80.6)$ & $128(75.3)$ \\
\hline Rural & $22(32.8)$ & $20(19.4)$ & $42(24.7)$ \\
\hline \multicolumn{4}{|l|}{ Educational status } \\
\hline No formal education & 14 (20.9) & 17 (16.5) & $31(18.2)$ \\
\hline Primary & $11(16.4)$ & $07(6.8)$ & $18(10.6)$ \\
\hline Secondary & $26(38.8)$ & $31(30.1)$ & 57 (33.5) \\
\hline Tertiary & $16(23.9)$ & $48(46.6)$ & $64(37.7)$ \\
\hline \multicolumn{4}{|l|}{ Marital status } \\
\hline Married & $31(46.7)$ & $42(40.8)$ & 73 (42.9) \\
\hline Single & $17(25.4)$ & $31(30.1)$ & $48(28.2)$ \\
\hline Widowed & $12(17.9)$ & 19 (18.5) & $31(18.2)$ \\
\hline Divorced & 07 (10.5) & $11(10.7)$ & $18(10.6)$ \\
\hline \multicolumn{4}{|l|}{ Occupation } \\
\hline Civil servant & 18 (26.9) & $47(45.6)$ & $65(38.2)$ \\
\hline Private employment & $16(23.9)$ & $30(29.1)$ & $46(27.1)$ \\
\hline Artisan & $05(7.5)$ & $06(5.8)$ & $11(6.5)$ \\
\hline Unemployed & $22(32.8)$ & $12(11.7)$ & $34(20.0)$ \\
\hline Student & $06(9.0)$ & 08 (7.8) & $14(8.2)$ \\
\hline
\end{tabular}

use was uncommon among study participants even among married couples, almost half of the HAART naive and substantial proportion of HAART experienced couples never used condom while having sex with their spouses. Few participants (13.4\% vs. 16.5\%) HAART naive and experienced respectively always used condom with their spouses. Inconsistent condom use among HAART naive and experienced partners was $38.8 \%$ and $41.8 \%$ respectively. The sexual behaviour, pattern of condom use among spouses, boyfriend/girl friend and those that engages in casual sex with others is as shown in Table 2.

\subsection{Patients' Characteristics Associated with Condom Use}

The prevalence of condoms use (always and inconsistent), was significantly higher among females (65.4\%) than males (48.2\%). The proportion of patients who reported condom use was similar across the age groups ( $\mathrm{p}=$ 0.530). There was no difference in condom use between urban and rural dwellers ( $\mathrm{p}=0.931)$.

The level of condom use increases with literacy level, but fails to reach statistical significance $(p=0.088)$. Spouse notification of HIV sero-status was significantly associated with use of condoms p $=0.02$; OR 1.32, 95\% CI: 1.06 - 1.64.With respect to partners' sero-status, condom use among discordant and sero-concordant partners 
Table 2. Sexual behaviour and condom use among participants.

\begin{tabular}{|c|c|c|c|}
\hline & $\begin{array}{l}\text { HAART naive } \\
\text { No (67) }\end{array}$ & $\begin{array}{c}\text { HAART experienced } \\
\text { No (103) }\end{array}$ & p-value \\
\hline \multicolumn{4}{|l|}{ Had multiple sex partners } \\
\hline No & $31(46.3)$ & $63(61.2)$ & 0.080 \\
\hline Yes & $36(53.7)$ & $41(39.8)$ & 0.105 \\
\hline Mean no of sexual partners & $3.06 \pm 1.87(2-10)$ & $3.04 \pm 1.51(2-8)$ & \\
\hline Males & $2.59 \pm 1.23(2-7)$ & $3.19 \pm 1.52(2-8)$ & \\
\hline Females & $3.67 \pm 2.35(2-10)$ & $2.91 \pm 1.63(2-8)$ & \\
\hline \multicolumn{4}{|l|}{ Partner enrolment } \\
\hline yes & $23(34.3)$ & $36(35.0)$ & 0.999 \\
\hline Discordant & $07(10.5)$ & $12(11.7)$ & 0.999 \\
\hline Smoking & $07(10.5)$ & $12(11.7)$ & 0.999 \\
\hline Alcohol & $06(9.0)$ & $13(12.6)$ & 0.632 \\
\hline Mean time of illness to Diagnosis (months) & $9.54 \pm 7.84(2-24)$ & $16.31 \pm 22.60(1-96)$ & \\
\hline \multicolumn{4}{|l|}{ Exchange sex for money } \\
\hline No & $52(77.6)$ & $72(69.9)$ & 0.354 \\
\hline Yes & $10(14.9)$ & $25(24.3)$ & 0.198 \\
\hline No comment & $05(7.5)$ & $09(8.7)$ & 0.999 \\
\hline \multicolumn{4}{|l|}{ Exchanged money for sex } \\
\hline No & $54(80.6)$ & 73 (70.9) & 0.214 \\
\hline Yes & $10(14.9)$ & $17(16.5)$ & 0.949 \\
\hline No comment & $03(4.5)$ & $13(12.6)$ & 0.134 \\
\hline \multicolumn{4}{|l|}{ Condom use } \\
\hline \multicolumn{4}{|l|}{ Sex with spouse } \\
\hline Never used condom & $32(47.8)$ & $41(39.8)$ & 0.384 \\
\hline Sometimes use condom & $26(38.8)$ & $43(41.8)$ & 0.819 \\
\hline Always use condom & $09(13.4)$ & 17 (16.5) & 0.741 \\
\hline Sex with boyfriend/girl friend & No $=31$ & No $=62$ & \\
\hline Never used condom & $13(41.9)$ & $26(41.9)$ & 0.999 \\
\hline Sometimes use condom & $16(51.6)$ & $25(40.3)$ & 0.416 \\
\hline Always use condom & $02(06.5)$ & $11(17.7)$ & 0.250 \\
\hline Sex with others & No $=26$ & No $=47$ & \\
\hline Never used condom & $12(46.2)$ & $22(46.8)$ & 0.999 \\
\hline Sometimes use condom & $13(50.0)$ & $18(38.3)$ & 0.417 \\
\hline Always use condom & $01(3.8)$ & 07 (14.9) & 0.297 \\
\hline
\end{tabular}

was similar $(\mathrm{p}=0.889)$. In terms of occupation, the highest rate of condom use was found among public/civil servants (68.9\%). Smoking and alcohol consumption was not associated with condom use in our cohort. The stepwise logistic regression indicated that female gender (OR 2.40; CI: 1.09 - 3.82), partner notification of HIV seropositive status (OR 1.32; CI: 1.06 - 1.64, yes versus none), occupation as a civil servant (OR 1.40; CI: 0.15 1.05), are factors independently associated with condom use in our studied participants. Table 3 depicts factors associated with condom use in the study population.

Figure 1 Shows the distribution of condom use according to literacy level. It indicates that condom use increases with educational attainment, although it falls short of statistical significance on stepwise logistic regression analysis. 
Table 3. Report of condom use according to selected characteristics among all study participants.

\begin{tabular}{|c|c|c|c|c|c|c|c|c|}
\hline \multirow{2}{*}{ Variable } & \multirow{2}{*}{ No (\%) } & \multirow{2}{*}{ SE } & \multirow{2}{*}{ Wald } & \multirow{2}{*}{ Exp (B) } & \multicolumn{3}{|c|}{ 95\%CI for $\operatorname{Exp}(\mathrm{B})$} & \multirow{2}{*}{ p-value } \\
\hline & & & & & (Lower & - & upper) & \\
\hline \multicolumn{9}{|l|}{ Sex } \\
\hline Male & $40(48.2)$ & 1 & & & & & & \\
\hline Female & $53(65.4)$ & 0.32 & 4.91 & 2.04 & 1.09 & - & 3.82 & $0.027^{*}$ \\
\hline \multicolumn{9}{|l|}{ Age group } \\
\hline $18-25$ & $12(63.2)$ & 1 & & & & & & \\
\hline $26-35$ & $35(52.2)$ & 0.66 & 1.44 & 0.45 & 0.12 & - & 1.65 & 0.530 \\
\hline $36-45$ & $34(55.7)$ & 0.79 & 2.98 & 0.26 & 0.55 & - & 1.20 & \\
\hline $45-55$ & 07 (58.3) & 1.04 & 0.74 & 0.41 & 0.53 & - & 3.14 & \\
\hline $46-65$ & $04(100)$ & - & - & - & & & & \\
\hline \multicolumn{9}{|l|}{ Residence } \\
\hline Urban & $71(56.4)$ & 1 & & & & & & \\
\hline Rural & $24(58.5)$ & 0.31 & 0.01 & 0.97 & 0.46 & - & 2.05 & 0.931 \\
\hline \multicolumn{9}{|l|}{ Educational status } \\
\hline None & $11(37.9)$ & 1 & & & & & & \\
\hline Primary & 09 (52.9) & 0.83 & 1.27 & 1.63 & 0.40 & - & 6.60 & 0.088 \\
\hline Secondary & 38 (67.9) & 0.59 & 5.90 & 0.77 & 0.18 & - & 3.38 & \\
\hline Tertiary & 35 (56.7) & 0.65 & 1.15 & 0.39 & 0.78 & - & 1.97 & \\
\hline \multicolumn{9}{|l|}{$\begin{array}{c}\text { Partner } \\
\text { HIV status notification }\end{array}$} \\
\hline yes & $40(70.0)$ & & & 1.32 & 1.06 & - & 1.64 & $0.020^{*}$ \\
\hline no & $53(49.5)$ & 1 & & & & & & \\
\hline \multicolumn{9}{|l|}{ Partner serostatus } \\
\hline Discordant & $11(57.9)$ & 0.51 & 0.02 & 1.07 & 0.39 & - & 2.91 & 0.889 \\
\hline seroconcordant & $84(56.8)$ & & & & & & & \\
\hline \multicolumn{9}{|l|}{ Smoking } \\
\hline yes & $12(63.2)$ & 0.52 & 0.23 & 1.29 & 0.46 & - & 3.63 & 0.631 \\
\hline no & $83(56.7)$ & & & & & & & \\
\hline \multicolumn{9}{|l|}{ Alcohol } \\
\hline yes & $12(63.2)$ & 0.53 & 0.18 & 1.25 & 0.44 & - & 3.57 & 0.672 \\
\hline no & $82(56.2)$ & 1 & & & & & & \\
\hline \multicolumn{9}{|l|}{ Occupation } \\
\hline Civil servant & $42(68.9)$ & & & & & & & \\
\hline Private employment & $23(50.0)$ & 0.49 & 3.49 & 0.40 & 0.15 & - & 1.05 & $0.034^{*}$ \\
\hline Artisan & $06(54.6)$ & 0.83 & 3.72 & 0.20 & 0.04 & - & 1.03 & \\
\hline Unemployed & $12(40.0)$ & 0.64 & 8.73 & 0.15 & 0.04 & - & 0.53 & \\
\hline Student & $06(50.0)$ & 0.82 & 2.97 & 0.24 & 0.05 & - & 1.22 & \\
\hline
\end{tabular}

\section{Discussion}

There is dearth of reports on condom use and uptake among HIV clients in Nigeria. To our knowledge, this is the first hospital based cross sectional study designed to provide insight into the practice of condom use and associated risk factors among HIV positive clients in north-eastern Nigeria.

Our participants consisted of both HAART naive and experienced, this gave us an opportunity to make comparison and observe the effect of highly active antiretroviral therapy on modifications in their sexual behaviour. 


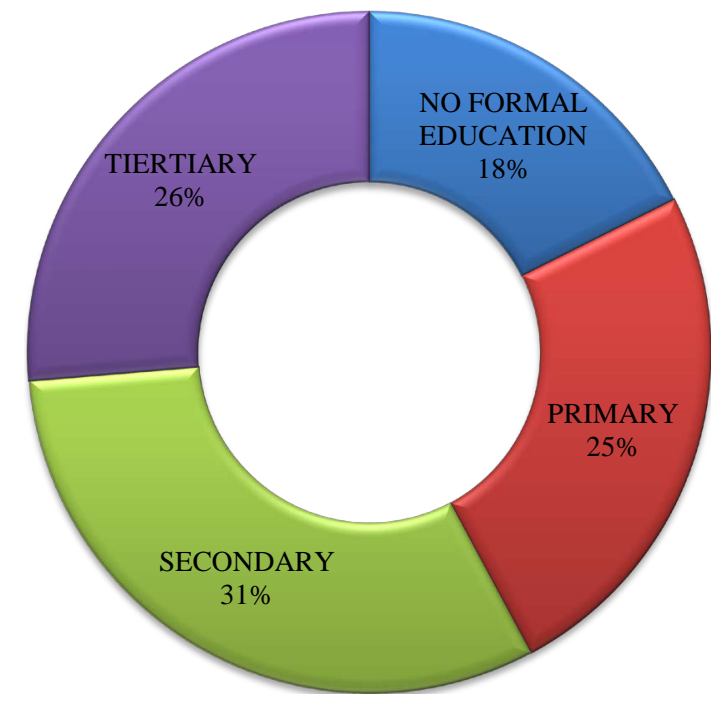

Figure 1. Distribution of condom use according to literacy level.

Most of our patients were residents of urban areas (75.3\%). A substantial proportion of the HAART naive cohort had secondary education (38.8\%), while Tertiary education was the predominant literacy level in HAART experienced cohort (46.6\%). Civil servants constituted the majority in HAART experienced, while unemployed cohort constituted one out of every three HAART naive patients (32.8\%). This finding suggests literacy level and gainful employment have a positive impact on accessing and continuing HIV care in our setting.

Married participants constituted $42.9 \%$ of the participants; they contributed the highest participants in both HAART naive and experienced cohort. At the time of the interview, $53.7 \%$ of HAART naive and $39.8 \%$ of HAART experienced participants had multiple sexual partners, with most of them in marital union. Condom use was uncommon among study participants even among married couples, almost half of the HAART naive and substantial proportion of HAART experienced never used condom while having sex. The finding of low condom use among the HAART experienced cohort in this study was surprising, considering the fact that regular counselling on adherence and condom use are provided to clients at initial assessment, commencement of HAART and as part of health talk at each clinic visit. Condom provided by the United State Government through the PEPFAR (Presidential Emergency Plan for AIDS Relief in Africa) is available free of charge on demand by clients in our HIV clinic. The low prevalence of condom use in our cohort is however similar to the proportion in HAART naive reported in south-western Nigeria [13] and National HIV/AIDS and Reproductive Health Survey (NARHS) [6], but unlike report from the southwest, we did not observed association between uptake condom and HAART use. Although reports from developed nations documented that access to HAART to be associated to reduction in risky behaviour including increased condom use [8] [9] [14], assessment of condom use in 20 countries in sub-Saharan Africa, indicated that levels of condom use are still very low and vary widely [15].

When they were asked to cite the reasons for not using a condom in the past 3 months, the main reasons given was that their partner did not want to use it because its use decreases sexual satisfaction or desire to have a child. Low condom uptake among HIV clients has a negative impact in HIV/AIDS prevention.

Overall, although risky sexual behaviour was observed among the study participants, there was no difference in the pattern of risky behaviour with respect to gender within a group. When subjects reported having casual partners, in all cases interviewed, they did not know their HIV sero-status. We observed that male participants continue or increase their risky sexual behaviour after knowing their HIV sero-status as significantly more females had multiple sexual partners in the HAART naive and males in the HAART experienced cohort. Female patients among HAART naive group were more prone to high-risk behaviour. This may be a result of poor socioeconomic status and lack of bargaining power of women and those who are not in a stable union. For instance, it may be difficult for a female who provided sex for money to negotiate condom use.

The level of condom use increased with literacy level, our finding is in agreement with similar studies in subSaharan Africa, [13]-[18] we found that participants with secondary education or higher were more likely to use 
condoms with a sex partner. Individuals with more education might have higher levels of HIV/AIDS knowledge and are less likely to have stigma towards HIV/AIDS, thus enabling them to easily change risky sexual behaviour [17] [18]. Additionally, individuals with higher education might be able to seek and accept information that would help protect their partners and themselves from HIV and STI transmission and re-infection [17].

Our data showed a strong association between disclosure of HIV status and protective patterns of condom use. This finding is consistent with previous studies that found that disclosure was associated with reduced transmission risk behaviours [19] [20]. For instance, a study in Cape Town, South Africa found that people who had not disclosed their HIV status to partners reported more sex partners and more unprotected vaginal and anal intercourse than people who had disclosed [19]. Therefore, interventions targeted to HIV-positive individuals must strengthen preventive altruism, promote HIV-status disclosure and assess issues relating to non disclosure [21] [22].

In terms of occupation, the highest rate of condom use was found among public/civil servants (68.9\%). In this population, it appears that smoking and alcohol do not affect condom use, as reported in other studies conducted in other countries [23] [24].

\section{Limitations}

Sexual behaviour was self-reported and subject to both recall and social desirability bias. In order to minimize the recall bias, we used 3-month recall period. We also tried to address social desirability bias by assigning male data collectors for male subjects and female data collectors for female subjects. Still we believe that the traditional reluctance to discuss sexual behaviour, especially homosexuality, is regarded as a taboo that may have resulted in underreporting.

\section{Conclusion}

We report that condom use is uncommon among HIV clients in our environment. Condom use is significantly influenced by partner notification, occupation as a civil servant and female. This study supports an absence of association between condom uptake and HAART use.

\section{Recommendation}

Factors militating against condom use among HIV clients should be individually and confidentially addressed during counselling, with greater emphasis on its positive impact and strengthening condom use negotiation. We recommend interventions directed at increasing condom use among HIV clients in our environment.

\section{References}

[1] Herek, G.M. (1999) AIDS and Stigma. American Behavioural Scientist, 42, 1106-1116. http://dx.doi.org/10.1177/00027649921954787

[2] Shisana, O., et al. (2005) South African National HIV Prevalence, HIV Incidence, Behaviour and Communication Survey. HSRC Press, Cape Town.

[3] Simbayi, L.C., et al. (2007) International Stigma, Discrimination, and Depression among Men and Women Living with HIV/AIDS in Cape Town, South Africa. Social Science \& Medicine, 64, 1823-1831. http://dx.doi.org/10.1016/j.socscimed.2007.01.006

[4] Kanki, P.J. and Adeyi, O. (2006) The impact of the Epidemic in Nigeria. In: Adeyi, O., Kanki, P.J., Odutolu, O., Idoko, J.A., Eds., AIDS in Nigeria: A Nation on the Threshold. Cambridge Harvard Centre for Population and Development Studies, 7-8.

[5] Federal Ministry of Health (2005) Technical Report on the 2005 National HIV/Syphilis Sentinel Survey among Pregnant Women Attending Antenatal Clinics in Nigeria. Federal Ministry of Health Abuja, Nigeria.

[6] Federal Ministry of Health (2010) HIV/STI Integrated Biological and Behavioural Surveillance Survey 2010. Federal Ministry of Health Abuja, Nigeria.

[7] Denue, B.A., Abja, A.U., Kida, I.M., Gabdo, A.H., Bukar, A.A. and Akawu, C.B. (2013) Evaluating Total Lymphocyte Counts and Other Hematological Parameters as a Substitute for CD4 Counts in the Management of HIV Patients in Northeastern Nigeria. Retrovirology: Research and Treatment, 5, 9-15. http://dx.doi.org/10.4137/RRT.S11562

[8] Crepaz, N., Hart, T.A. and Marks, G. (2004) Highly Active Antiretroviral Therapy and Sexual Risk Behaviour: A Meta 
Analytic Review. JAMA, 292, 224-236. http://dx.doi.org/10.1001/jama.292.2.224

[9] Wilson, T.E., Gore, M.E., Greenbatt, R., et al. (2004) Changes in Sexual Behaviour among HIV-Infected Women after Initiation of HAART. American Journal of Public Health, 94, 1141-1145. http://dx.doi.org/10.2105/AJPH.94.7.1141

[10] WHO (2010) Antiretroviral Therapy for HIV Infection in Adult and Adolescent: Recommendation for Public Health Approach-2010 Revision.World Health Organization, Geneva.

[11] Kennedy, C., O’ Relly, K., Medley, A. and Sweat, M. (2007) The Impact of HIV Treatment on Risk Behaviour in Developing Countries: A Systemic Review. AIDS Care: Psychological and Socio-medical Aspects of AIDS/HIV, 19, 707-720. http://dx.doi.org/10.1080/09540120701203261

[12] Venkatesh, K.K., Flanigan, T.P. and Mayer, K.H. (2011) Is Expanding HIV Treatment Preventing New Infections? Impact of Antiretroviral Therapy on Sexual Risk Behaviours in the Developing World. AIDS, 25, 1939-1946. http://dx.doi.org/10.1097/QAD.0b013e32834b4ced

[13] Akinyemi, J.O., Awolude, O.A., Adewole, I.F. and Kanki, P.J. (2010) Condom Use among Antiretroviral Therapy Patients in Ibadan, Nigeria. Journal of Infection in Developing Countries, 4, 495-502.

[14] Dukers, N.H., Goudsmit, J., de Wit, J.B., Prins, M., Weverling, G.J. and Coutinho, R.A. (2001) Sexual Risk Behaviour Relates to the Virological and Immunological Improvements during Highly Active Antiretroviral Therapy in HIV-1 Infection. AIDS, 15, 369-378. http://dx.doi.org/10.1097/00002030-200102160-00010

[15] Amouzou. A. (2003) Regional Variation and Cross-Country Determinants of Condoms Use in Sub-Saharan Africa. Paper Presented at the Seminar on Taking Stock of the Condom in the Era of HIV/AIDS, Gaborone, July 2003.

[16] Ukwuani, F.A., Tsui, A.O. and Suchindran, C.M. (2003) Condom Use for Preventing HIV Infection/AIDS in Sub-Saharan Africa. Journal of Acquired Immune Deficiency Syndromes, 34, 203-213. http://dx.doi.org/10.1097/00126334-200310010-00011

[17] Volk, J.E. and Koopman, C. (2001) Factors Associated with Condom Use in Kenya: A Test of the Health Belief Model. AIDS Education and Prevention, 13, 495-508. http://dx.doi.org/10.1521/aeap.13.6.495.21438

[18] Benefo, K.D. (2010 Determinants of Condom Use in Zambia: A Multilevel Analysis. Studies in Family Planning, 41, 19-30. http://dx.doi.org/10.1111/j.1728-4465.2010.00221.x

[19] Simbayi, L.C., Kalichman, S.C., Strebel, A., Cloete, A., Henda, N. and Mqeketo, A. (2007) Disclosure of HIV Status to Sex Partners and Sexual Risk Behaviors among HIV-Positive Men and Women, Cape Town, South Africa. Sexually Transmitted Infections, 83, 29-34. http://dx.doi.org/10.1136/sti.2006.019893

[20] Deribe, K., Woldemichael, K., Wondafrash, M., Haile, A. and Amberbir, A. (2008) High-Risk Behaviors and Associated Factors among HIV-Positive Individuals in Clinical Care in Southwest Ethiopia. Tropical Doctor, 38, $237-239$.

[21] King-Spooner, S. (1999) HIV Prevention and the Positive Population. International Journal of STD \& AIDS, 10, 141150. http://dx.doi.org/10.1258/0956462991913763

[22] Kiene, M.S., Christie, S., Corman, D.H., et al. (2006) Sexual Risk Behavior among HIV-Positive Individuals in Clinical Care in Urban KwaZulu-Natal, South Africa. AIDS, 20, 1781-1784. http://dx.doi.org/10.1097/01.aids.0000242827.05120.55

[23] Dave, S.S., Stephenson, J., Mercey, D.E., Panahmand, N. and Jungmann, E. (2006) Sexual Behavior, Condom Use, and Disclosure of HIV Status in HIV Infected Heterosexual Individuals Attending as Inner London HIV Clinic. Sexually Transmitted Infections, 82, 117-120. http://dx.doi.org/10.1136/sti.2005.015396

[24] Clark, R.A., Kissinger, P., Bedimo, A.L., Dunn, P. and Albertin, H. (1997) Determination of Factors Associated with Condom Use among Women Infected with Human Immunodeficiency Virus. International Journal of STD \& AIDS, 8, 229-233. http://dx.doi.org/10.1258/0956462971919976 